\title{
Decolonizing Research on Heritage Language Maintenance and Loss: Narrating Linguistic Experiences
}

\author{
Nataliya Kharchenko \\ University of Manitoba
}

\begin{abstract}
The following paper attempts to position a topic of heritage language maintenance and loss from a perspective of postcolonial qualitative research, addressing the issues of voice, and some advantages and limitations of narrative inquiry and interviews as possible research methods. Qualitative research on heritage languages will share most features with the traditional qualitative research, but at the same time will adopt some peculiar additional nuances due to its anti-oppressive and decolonizing stance. Personal interviews and reflective narratives are appropriate methods in the research on heritage language maintenance and loss; however, they are not deprived of limitations.
\end{abstract}

Keywords: qualitative research, decolonizing research, heritage language maintenance, narrative inquiry, interviews.

\section{DECOLONIZING RESEARCH ON HERITAGE LANGUAGES: NARRATING LINGUISTIC EXPERIENCES}

"Chinese is the language with the deepest emotional resonance for me. It was the only language which mattered, and I think of it as the language of my heart. Perhaps that's why, even now, when I cry, I cry in Chinese" (Ho, 2000, p.161).

The above epigraph belongs to a proficient speaker and writer of English who, despite living and creating in a second language, still feels more attachment to a mother tongue. This is also true for millions of immigrants, who irrespectively of their long residence in host countries and fluency in a second language are still thinking, dreaming, and "crying" in languages other than English. According to Statistics Canada (2014), in 2011 there were more than 200 languages including English used in Canadian homes and families. Taking into account the rather narrow definition of "mother tongue" provided by Statistics Canada as the language "learned at home in childhood and still understood at the time of the census", we may assume the number will be higher if they account for those speakers not fully proficient in their heritage languages but who still feel personal connections to languages other than the mainstream ones. We probably do not even have to refer to statistics or research data to realize that we are surrounded by a myriad of languages; the never ending cacophony of strange unfamiliar languages interspersed with English on a bus, in our neighbourhood, and in grocery stores became a norm of life in a multicultural and multilingual society.

While multilingualism is a natural consequence of a wide-spread relocation of population, it is not celebrated everywhere; in some countries it is tolerated at best, in other places accents and limited proficiency in a mainstream language are perceived as a stigma, restricting immigrants in their choices, and forcing them to give up their first languages and switch to a dominant one for the mere purpose of survival. The idea of adopting bilingual and bicultural identities by positioning yourself somewhere in between two cultures and languages (Kanno, 2003) would 
be an ideal solution not only for international students, but also for those who come to a new country for good. Unfortunately, reality of a host country dictates its own rules making the perfect alternative of bicultural and bilingual identities almost always impossible for both newcomers and their subsequent generations. It is virtually unrealistic for new immigrants to adopt bilingual identity due to their accents and limited competency in a dominant language; moreover, the ESL programs which are aimed at supporting and providing smooth transitions into the society, make it even harder for new ESL learners to integrate and find friends in a dominant culture (Kanno, 2003), thus limited cultural exposure and interaction with native speakers can make a bicultural identity for first generation immigrants almost a myth. While communicating with international students who were planning to return eventually to their home country, Kanno (2003) noted that despite their high English language proficiency and relatively long time of residence in an English-speaking country, they still could not claim that English was one of "their" languages.

Unlike sojourners and international students who come to a host country only temporally and may possibly belong to a dominant society without "sacrificing part of oneself" (Kanno, 2003), immigrants do need to make this sacrifice, and usually this "part" is their first language. Contemplating on deteriorated relationships with his parents, Rodriguez (1983) acknowledged that he was "a comic victim of two cultures" and did not believe in bilingualism proclaimed in a dominant society. In his autobiography, the author attempts to prove that education was the main cause of his alienation from family. Since he became a "scholarship boy" and achieved his $\mathrm{PhD}$, he was distant to his parents, immigrants of Mexican origin who had only basic skills and limited literacy in English. He seems to underestimate the role of a heritage language, or rather his loss of it, which contributes even more to this alienation. As he admits on the very last page of his book, when the family gathered for Christmas, and then all the adult children left, his father inquired if Richard was going home as well. At this point Richard realized that it was "the only thing he [his father] has said to me all evening" (p.195). By trying to depicture his parents as loving and caring, he still presents numerous memories of the situations when his parents were humiliated or felt less educated due to their limited knowledge of English. He was happy as a child when the primary language of communication with his family members was Spanish; they were united as a family; even as a child, he could differentiate the foreign strange language (English) of the outside world, and the intimate language of the family life. After his teachers (nuns) strongly advised his parents to switch to English as a family language, the life and dynamics in their family changed forever:

We remained a loving family, but one greatly changed. No longer so close; no longer bound tight by the pleasing and troubling knowledge of our public separateness. Neither my older brother nor sister rushed home after school anymore. Nor did I (Rodriguez, 1983, p.23).

He did not even know how to address his parents since he was not able to use Spanish words for mother and father anymore; on the other hand, English versions were also alienating for him and did not have any emotional attachment. At the same time his parents became quiet as they could no longer communicate with their children with the easiness they used to have in Spanish; their English was simply not enough to continue that intimate interaction with their children. Sharing her personal story of mothering in a second language, Kouritzin (2000) notes "in Japanese, there is an artificiality about my love; I cannot express it naturally or easily. The emotions I feel do not translate well into the Japanese language ..." (p. 314). 
If a heritage language is not available in the domain of a family and society, then the only choice could be heritage schools, but they also do not guarantee language maintenance. Kanno (2003) believes that only separate schools run by a specific linguistic and ethnic community may be efficient because children can see that their mother tongue is valued, validated, and is considered to be the norm. Moreover, the academic component adds significance to language maintenance not only at a basic conversational level (Kanno, 2003). Usually, if parents are committed to maintaining their first language, they would engage all possibilities, but there is another scenario, when either ignorance or desire to integrate successfully in the host society prevails the priority of heritage language maintenance, then pressured by external forces and inner dilemmas, people gradually lose what they used to call their first language. They think English is an empowering language which opens new doors and offers the possibility to gain status in a new country; on the other hand, empowerment by English is accompanied by marginalization. Not having native-like proficiency in English and deprived of their mother tongue, immigrants are somewhere in between, having left one bank of the river, but still floating and not able to reach the other. Fishman explains the challenges for reversing language shift by the fact that usually it is the preoccupation of powerless minorities who are often outsiders in the mainstream society, so quite often their linguistic efforts are not successful and may be viewed by the dominant groups as "unnatural", violating some societal natural course of events and changes (Hornberger \& Putz, 2006), whereas intergenerational heritage language maintenance should be viewed as "a cultural right and a societal resource" (Fishman, 1991, p.7).

Usually the definitions of heritage or mother languages are based on either functions (the language a person uses most) or competence (the language a person knows best), but Skutnabb-Kangas and Bucak (1995) view a mother tongue from the perspective of linguistic human rights as one or more languages that "one has learned first and identifies with" (p.361), thus, suggesting that an individual may have more than one mother language. Heritage languages are connectors to one's ancestry and indispensable identity markers, so once the language is lost, "the cultural content that the ethnic language carried is never fully recoverable" (Dorrian, 1999, p. 34). Mistakenly, second or third-generation grandchildren of immigrants believe they can regain their heritage language easier than those who have no family connections to it (Dorrian, 1999); unfortunately, our heritage language cannot be automatically transferred with genes or some ancestral blood memory.

The following paper will attempt to position a topic of heritage language maintenance and loss from a perspective of postcolonial qualitative research, addressing the issues of voice, insider/outsider debates and some advantages and limitations of narrative inquiry and interviews as possible research methods.

\section{MULTILINGUALISM AS MONOLINGUALISM}

Despite the proclaimed commitment to multilingualism and multiculturalism in host societies, many researchers voice their criticism regarding the dual nature of somewhat hypocritical attitudes to multilingualism within a predominantly monolingual mainstream society. Macedo and Bartolome (2014) point out the fact that proclaimed celebration of other cultures is a form of paternalism which happens through the medium of English mostly, subordinating other linguistic minorities; moreover, promoting and teaching cultural tolerance is more like a gift to "others" strengthening the power imbalance between those who are privileged to condescendingly tolerate and put up with other languages, cultures and ethnic minorities. These policies bear intangible traces of colonial strategies which devalued the cultures and languages of the colonized (Macedo \& Bartlome, 2014). 
Multicultural reality would be influenced by the number of linguistic groups involved as well as the power relations between them; in practice, multilingualism implies acquisition of a mainstream language for successful integration of language minorities into the dominant society (Hoosain \& Salili, 2005). Taking into consideration our present globalized world, multilingualism should not be prescribed to language minorities only, but must be a priority for majority groups as well promoting diversity not only within one particular society but also in globalized community (Hoosain \& Salili, 2005).

Kubota (2005) indicates the populist and declarative nature of multilingual diversity often mentioned within the educational context, but not something educators are compelled to put into practice. In a predominantly monolingual society there is also a duality towards bilingualism or multilingualism for dominant majority groups and subordinated minorities (Kubota, 2005; Macedo \& Bartlome, 2014). Multicultural education may acquire elitist nature privileging majority monolingual groups with additional foreign languages viewed as assets, while further marginalizing linguistic minorities whose bi-/multilingualism is seen as a problem that should be solved by acquiring the dominant language (English); consequently, bilingualism for native speakers of English is "additive", while for language minorities it is "subtractive" (Kubota, 2005). On the other hand, bilingualism may also have two forms: the first one is considered to be formal, acquired by means of official schooling and implied literacy; the second one is informal, typically associated with home languages of immigrant children who may not have substantial formal education in their native language and limited or no literacy skills. Kubota (2005) labeled the first type of bilingualism with capital "B", and the second one with small " $b$ " to illustrate two different facets of the same phenomenon; moreover, she asserts that the English-only ideology is implied in these two forms, depriving immigrant children of becoming "Bilingual" and leaving them no choice but become either "bilingual" or even monolingual English speakers who lose their first language (Kubota, 2005). Kouritzin (2006) asserts that "not allowing minority language children from socio-economically disadvantaged homes to reap the benefits of a bilingualism which should be their birthright is socially unjust" (p. 23). Addressing linguistic mix in African postcolonial reality, Baker (2005) pointed out that children educated by means of a former colonial language (English) and communicating in their local native languages outside of school context end up not being proficient enough in either language, so they do not possess enough literacy skills to seek wellpaid jobs in the future. Although educators, parents and children value their first languages, they are still compelled to seek English-medium educational opportunities to guarantee upwards mobility in postcolonial African context (Baker, 2005).

Another concept underlying multilingual education is pragmatism, or choosing the languages with the highest potential benefits for a specific society in a given context; as a result, some languages are privileged over others, which in turn emphasizes the unequal power distribution (Kubota, 2005). The symbolic power of languages was confirmed by Bourdieu (1977), who claimed that "linguists are right in saying that all languages are linguistically equal; they are wrong in thinking they are socially equal" (p.652, as cited in Kanno, 2003, p. 5). All in all, the societal attitudes and understanding of multiculturalism and multilingualism may also be a contributing factor in either heritage language maintenance or loss.

\section{QUALITATIVE RESEARCH ON HERITAGE LANGUAGE MAINTENANCE AND LOSS}

The choice of qualitative methods in research on heritage language maintenance and loss is justified by the fact that we focus on human life, identity, sense of belonging or alienation, pain, loss, and disconnectedness. We are not measuring our participants' heritage language 
proficiency; rather, we look at how they live with the language or without it. Our purpose is not the same as that of the English language proficiency tests evaluating competence in L2 in order for newcomers to gain access into educational system or the host society in general. Heritage languages should not be viewed as an indicator of a full participation in L1 community, but rather as some crucial connections and relationships in human life.

Qualitative research on heritage languages will share most features with the traditional qualitative research, but at the same time will adopt some peculiar additional nuances due to its anti-oppressive and decolonizing stance. Denzin and Lincoln (1994) define qualitative research as:

multimethod in focus, involving an interpretive, naturalistic approach to its subject matter. This means that qualitative researchers study things in their natural settings, attempting to make sense of, or interpret, phenomena in terms of the meanings people bring to them (p.2).

Taking into account the wide range of empirical materials and methodologies employed by qualitative researchers, their final product may be compared with "bricolage" (Denzin \& Lincoln, 1994), a borrowed French term to name a creation or piece of work compiled of all available materials. Although Denzin and Lincoln (1994) call a qualitative researcher the "bricoleur", they caution that different theoretical paradigms may not be mixed easily since they represent specific ontological and epistemological views, so they propose to replace paradigms with "perspectives", leaving some room for flexibility and concluding that "the researcher-as-bricoleur-theorist works between and within competing and overlapping perspectives and paradigms" (Denzin \& Lincoln, 1994, p.3).

While qualitative researchers may have a wide scope of options in terms of theoretical frameworks and methods of data collections, it does not automatically mean that anything can work; one mix of methods may be successful in some specific context to solve a definite problem, but may turn to be a complete failure under different circumstances. I would agree with the claim of employing multiple paradigms and methods, but not because of the initial openness of qualitative research or lack of rigorous criteria for research design, rather this broad range of possibilities may be viewed as a necessity caused by the nature of qualitative research which explores experiences, meanings, understandings of a myriad of human phenomena which will not definitely fit within one or two theoretical paradigms; in other words, "bricolage" is as multiple as human life experiences interpreted by qualitative research.

Qualitative research is viewed as an "interactive process" between a researcher with his or her cultural, social and ethnic background, and the participants (Creswell, 2007). The final result, "bricolage", is viewed as a mosaic of "the researcher's images, understandings, and interpretations of the world or phenomenon under analysis" (Denzin \& Lincoln, 1994, p.3). This definition is somehow incomplete because in a decolonizing qualitative research, including research on heritage language maintenance and loss, it is not enough just to represent a researcher's understanding of the phenomenon because then this would be a replication of a traditional colonial practice of silencing the participants or the "other" while using their knowledge and information to benefit the ambitions of the researcher only. Decolonizing research should find a way to weave the voices of everyone involved, including the participants, because the knowledge production and interpretation is a mutual process, not only a prerogative of an academic onlooker who acts as a knowledgeable researcher. 
Qualitative research also is not about measuring since the emphasis in on meanings and processes (Denzin \& Lincoln, 1994).

According to Denzin and Lincoln (1994), there are two ongoing crises in terms of qualitative research: "the representational" and "the legitimation crisis". The first one reflects the impossibility of objective and accurate representation of the lived experience because literally it is only the researcher's text or writing that may disguise the actual reality. The legitimation crisis deals with the problematic traditional criteria of research evaluation such as validity, generalizability and reliability, which are not directly applicable or relevant for qualitative research (Denzin \& Lincoln, 1994). Interpretive techniques based on poststructuralism and postmodernism deny the existence of any objective reality or any possibility of an accurate and single interpretation:

Any gaze is always filtered through the lenses language, gender, social class, race, and ethnicity. There are no objective observations, only observations socially situated in the worlds of the observer and the observed. Subjects, or individuals, are seldom able to give full explanations of their actions or intentions; all they can offer are accounts, or stories, about what they did and why. No single method can grasp the variations in ongoing human experience (Denzin \& Lincoln, 1994, p. 12).

The most common features of qualitative research are: naturalistic setting; multiple sources of data collection; inductive and interpretive nature of data analysis; attention to participants' voices and perspectives; evolving design; situatedness within a particular cultural, historical and social context; tentative conclusions without claims for objectivity; focus on the process of meaning making rather than on the final product (Bogdan \& Biklen, 2003; Creswell, 2007).

The acknowledgement of existence of multiple interpretations located in a situated context opens the possibility for multiple criteria for evaluation of qualitative research in numerous communities. The future implications for qualitative research will involve prospects of emerging of new multivoiced texts, new forms of writing and interpretation, and a higher emphasis on reflectivity (Denzin \& Lincoln, 1994). This uncertainty, on the one hand, may be intimidating due to its vagueness and absence of clear standards and criteria; on the other hand, it leads to new yet unknown possibilities and exploration of meanings through new perspectives. Lincoln and Denzin (1994) outline the future prospects of qualitative research:

Slowly it dawns on us that there may not be one future, one "moment", but rather many; not one "voice", but polyvocality; not one story, but many tales, dramas, pieces of fiction, fables, memories, histories, autobiographies, poems, and other texts to inform our sense of lifeways, to extend our understanding of the Other..." (p. 584).

\section{DECOLONIZING RESEARCH ON HERITAGE LANGUAGE MAINTENANCE AND LOSS}

In the context of global popularity and domination of English, the loss of mother tongue is a central issue in any decolonizing educational or cross-cultural discussion; simultaneously, "as more students prefer to learn in English, in part due to the power of corporate globalization, the persistence of language as a tool of colonization is obvious" (Mutua \& Swadener, 2004, p. 16). Research on language maintenance and loss positioned in postcolonial perspective aims at providing the opportunity to speak for those linguistic minorities who were deprived this chance due to their limited proficiency in a dominant language, or low symbolic power of their first languages. In general, decolonizing research is preoccupied with giving voice to all those 
formerly oppressed, subjugated or marginalized due to their economic status, race, language, gender, culture, or disability.

Debating over the main focus of decolonizing research, Macedo and Bartolome (2014) are rather critical of the motto to "give voice" since voice is not something to be given or taken away by the colonizers, it is a human right. Instead of waiting to be granted the possibility to have your own "voice", Smith (1999) promotes a more proactive agenda for Indigenous peoples "to tell an alternative story: the history of Western research through the eyes of the colonized" (p.2) when the past history of marginalization becomes a way of "resistance and hope". Smith (1999) addresses the possibility of research for Indigenous peoples as a part of their recovery process and becoming active participants in the world. Appadurai (1997) reiterates by presenting arguments for new research agenda that should focus on "the nature of locality as a lived experience in a globalized, deterritorialized world" (p.52), thus admitting the growing importance of community-based research by local people as opposed to researchers-outsiders. Appadurai (2006) advocates for the "right to research" as one of the human rights that is currently not available to the majority of population who are denied access to knowledge creation because of their marginal status. Only about $20 \%$ of the population, the so called "global elite", can participate in the knowledge construction and have virtually unlimited academic and career choices. Appadurai (2006) revisits the narrow traditional understanding of research as the production of new knowledge and ideas, and affirms that ordinary people should claim their right to research as "the tools through which any citizen can systematically increase that stock of knowledge which they consider most vital to their survival as human beings and to their claims as citizens" (Appadurai, 2006, p.168). Indigenous peoples then have their right to research as a way of resistance (Smith, 1999) and cultural, political, linguistic, and physical survival. Neumann (1997) view research as a general learning opportunity through communication between researchers and their participants and a subsequent contemplation on the part of a researcher.

Literacy is traditionally viewed as a prerequisite for the ability to produce counter discourse, to resist and to speak, so this traditional understanding of literacy is often an obstacle for Indigenous peoples and minorities who may not be considered qualified enough due to their limited academic abilities in the Western sense. Bhabha (1998) suggests a broader understanding of literacy "which is not merely about competence but is about intervention, the possibility of interpretation as intervention, as interrogation, as relocation, as revision" (as cited in Olson \& Worsham, 1998, p. 382). All in all, a new conception of research implies new attitudes to researcher positionality, new ways of meaning and knowledge construction from multiple localitites performed in order to hear the voices of the marginalized and validate their knowledge.

Due to multiplicity of voices from different communities and perspectives, there are no precise and consistent definitions of postcolonial studies, but they assuredly occupy an interdisciplinary position (Mutua \& Swadener, 2004). One of the major tasks of decolonizing project is to decolonize the Western academy with its traditional undervaluing of Indigenous methodologies and epistemology (Mutua \& Swadener, 2004).

The colonial practice of representing the "other", uncivilized, Indigenous, foreign or otherwise different from white powerful colonizers, is also applicable in terms of research practices, where the "other" is the object of research. Bell hooks (1990) eloquently expressed the silence of the "other": 
no need to hear your voice when I can talk about you better than you can speak about yourself. No need to hear your voice. Only tell me about your pain. I want to know your story. And then I will tell it back to you in a new way. Tell it back to you in such a way that it has become mine, my own. Re-writing you, I write myself anew. I am still author, authority. I am still the colonizer, the speak subject, and you are now at the centre of my talk. Stop (hooks, 1990, pp. 151-152 as cited in Fine, 1994, p. 70).

Over long time the "other" was represented by a foreign voice, stereotypical, fragmented, inaccurate and dominating. Fine (1994) states that the images of Self (the researcher) and the Other (the researched, or the informants) are inseparable and intertwined. Yet, by choosing to write "about those who have been Othered", researchers refuse to admit this interdependence and tensions permeating their texts. Alternatively, if researchers choose to write "with those who have been exploited and subjugated", the boundaries are merged and this is the way to "work the hyphen" (Fine, 1994, p. 72). In the process of "working the hyphen", researchers get the possibility to negotiate with their participants regarding meanings, interpretations and authorship of the stories being told in a complex mutual dependence between the context, informants and the researcher. If researchers prefer a distant neutral position of simply being the messengers who deliver the voices of homogenous Others, they continue reproducing "otherness", but if instead they choose to cooperate with the Other and explore their mutual interrelations, then there is a chance to produce resistance to the discourse of othering (Fine, 1994).

Another potential flaw is the attempt on the part of researchers to prescribe some fixed homogenous identities to both marginalized groups and those in power; consequently, the binaries are created of culturally homogenous groups in opposition to each other, but the inner conflicts and contradictions within the cultural and ethnic groups are overlooked (personal communication with Denzin, February 1992 as cited in Fine, 1994). Consequently, we should not be guided by one paradigm and assume that all racial minorities feel oppressed based on critical race theory, or that gender inequality is the reality everywhere and explains discriminatory practices, or that all immigrants are linguistic minorities and feel the need to be represented. Throughout our life span we may shift our positions depending on the social, cultural and historical contexts, so the same person may be in a dominant majority group in one place and in a subjugated minority in the other. In fact, both the dominant and minority groups may be unaware of their privileges or oppressed positions because for them it may be just an unquestionable fact of life. For example, being raised in a monocultural society, I was not aware that "whiteness" could be considered as a privilege or a sign of a higher position. On the other hand, majority group may be willing to sustain the status quo and not engage in the processes that may somehow shake their stable positions, for they feel threatened and refuse to admit the inequalities or power disbalance. In the latter case, the decolonizing research is projected not only for the sake of the oppressed, but simultaneously it should be preoccupied with those dominant or elite classes without whose involvement nothing can happen. Formally, the subjugated could be provided with the declarative opportunity to have a "voice", but it will be in vain if those in power do not pay attention. Ideally then, a researcher in a decolonizing project should be a medium who does not belong to either the dominant or the subjugated groups, and who may be a mediator in the negotiating processes. In any case, I think the decolonizing research involves not only the oppressed and the researcher; it should inevitably engage majority groups as well. 
Analyzing ways that may challenge traditional strategies in postcolonial educational research, Andreotti (2011) recommends acknowledging the privileged role of academia and researchers in the process of knowledge construction and building ethical relations with the communities accordingly; moreover, since knowledge construction is tentative, she recommends avoiding the tone of "speaking truth to the power". Postcolonial researchers should not try to find a "typical" case but rather should search for a "telling" case which may explain or add clarity to the former vague meanings (Mitchell, 1984 as cited in Andreotti, 2011).

The aim of educational postcolonial research is "to enable individuals to reflect critically on the legacies and processes of their cultures and contexts, to imagine and negotiate "otherwise", and to take ethical responsibility for their decisions and actions" (Andreotti, 2011, p.93). There are some strategies advisable for a postcolonial researcher: "learning to unlearn" implies analyzing the influence of socio-historical realities on our contexts, identities and knowledge production; " learning to listen" means being open to alternative possibilities and interpretations; "learning to learn" refers to being aware of what we do not know and being ready to step out of our comfort zone; "learning to reach out" is viewed as application of the new knowledge and meanings in our specific contexts and being in a constant pursuit of new ways of understanding and meaning making; finally, keeping in mind that knowledge is related to power relations in society and not every knowledge is beneficial, so sometimes knowledge may cause harm and contribute to unequal power distribution (Andreotti, 2011). The main objective of postcolonial research may be viewed as "eroding fixed categories and provoking possibilities for qualitative research that is designed against Othering, for social justice, and pivoting identities of Self and Other at the hyphen" (Fine, 1994, p.81). Jones and Jenkins (1998) view "hyphen" as a way of learning "from difference rather than learning about the Other" (as cited in Parker Webster \& John, 2010, p. 189).

A new feature of qualitative research is the seeking for some spirituality, or primordial sacredness that may contribute to our understanding and meaning making since the traditional rigorous academic approaches and science failed to provide comprehensive answers and solutions (Lincoln \& Denzin, 1994). Anti-oppressive research recognizes as valid other forms of knowledge (personal life experience for example) besides those published in books (Potts \& Brown, 2005). The same is applicable to decolonizing research practices that are in search of new ways of incorporating Indigenous ontology and spirituality not just for the sake of "giving the voice" to previously silenced, but also to contribute to the benefits of the broader academy and better understand human experiences and phenomenon in our yet unknown and mysterious world. Kovach (2005) admits that traditional approaches and methods of collecting data would not be replaced but enhanced by alternative ways of knowing, such as dreams for example; consequently, Indigenous methods lay claim to legitimacy within the academy.

Decolonizing research claims to empower the oppressed, subjugated and marginalized. Brown and Strega (2005) emphasize that in the context of research, marginalization is not limited to discrimination and lack of access to resources for some groups of the population; marginalization refers to inability of participating in the knowledge construction, being the objects of research rather than authors or co-creators of knowledge. By providing the opportunity for expressing one's voice, decolonizing research from the margins is not conducted on the subjugated, but "by, for, and with them" taking into account the oppositional discourses of domination and oppression within specific political context and legitimizing the ways of talking about people's life experiences for the purpose of making changes (Brown \& Strega, 2005, p. 7). 
Empowerment should not be defined in a simplistic way as "just "any change" or "outcome" benefiting an oppressed group" or a mere psychological state of comfort because such an attitude diminishes the significance of social, cultural and political nuances of the process (Delgado-Gaitan, 1997, p. 45). Empowerment cannot be granted or exchanged, it is not something that researchers can provide the participants in order to improve their status; rather empowerment is a process, an action, so "every time we unite with others to deal with common issue, it is an opportunity to empower ourselves. We are empowered when we feel in control of our lives" (Delgado- Gaitan, 1997, p.46). The role of a researcher in this case is probably limited to that of a mediator or a leader at best, but he or she should not take the full credit for elevating oppressed communities from their margins. Montero-Sieburth (1997) questions the possibility of researchers to empower communities but suggests that the value of research is in gaining knowledge from the communities in need who subsequently can reflect and use this knowledge to act on their own behalf; in this scenario, a researcher may act as "a catalyst to create the space within which others may discover their power" (p.126). By providing the example of her research participants who managed to unite their efforts and defend their linguistic rights, Delgado-Gaitan (1997) demonstrates that communities are able to achieve their goals by joining with the others. At the same time, as the researcher, she contributed to their process of unification and then stepped aside and assumed the role of an observer, so that the community could recognize their own successful achievements, not those of the researcher (Delgado- Gaitan, 1997); consequently, what is left for the researcher is the academic process of writing, analyzing and publishing.

Decolonizing research is first and foremost associated with Indigenous communities who make it both political and emancipatory; as a result, it can never employ neutral methodologies (Kovach, 2005). Aboriginal communities faced a long-term tradition of being only a passive object of the academic research done by outsiders, so in a postcolonial perspective they can no longer be silent material for research, they demand accountability on the part of researchers as well as becoming active researchers themselves (Absolon \& Willett, 2005; Smith, 1999). Decolonizing research for Indigenous peoples is determined not only by academic ambitions of seeking knowledge, but most vital is the agenda that includes revision of the past histories and knowledge creating alternative stories; ironically, Indigenous researchers should use "the language of the colonizer" in order to create alternative discourses and rely on Indigenous spirituality and methodology in order to survive, resist and recover (Smith, 1999). Indigenous scholars have additional challenges by using Western knowledge and languages while doing research in their communities ("double consciousness"), dealing with political and ethical complexities and multiple identities of researchers and participants in a postcolonial context (Jankie, 2004). Aboriginal research methodologies also imply reliance on the process rather than on the final product; the process of engagement with the community is of paramount importance (Absolon \& Willett, 2005).

Being involved in a postcolonial research project with the Indigenous communities, researchers should not homogenize and generalize because they deal with multiple cultures and languages: "we say Aboriginal peoples as a plural in order to denote our diversity" (Absolon \& Willett, 2005, p. 110). Researchers should also be cautious regarding which Indigenous knowledge can be shared through writing and being aware at the same time that English may not always have adequate ways of delivering Indigenous epistemology for nonnative audience (Absolon \& Willett, 2005). 
Researchers' positionality is definitely shaped by epistemological and ontological perspectives under specific contextual conditions. herising (2005) uses the term "politics of location" which may be interpreted as:

\begin{abstract}
a means of interrupting and accounting for the formulations and constructions of one's social-political locations. To do so requires the researcher not simply turn his gaze critically and reflectively inwards but rather to engage in critically reflective processes that speak to multiple power relations (p.133).
\end{abstract}

The task of a researcher is beyond simply reflexivity and reflection, for he or she is supposed to consider multiple factors that shape power relations and knowledge construction. Engaging in the inquiry of researchers' "politics of location", reflexivity is viewed as a crucial form of denying absolute truth and realizing that knowledge is tentative; moreover, "reflexivity of positionalities need to be an ongoing critical practice that refuses to accept compulsory and fixed identities" (herising, 2005, p. 147). Researchers should feel accountability for the communities they engage with and be cautious as not to reproduce colonial practice in the process of their research (herising, 2005).

Potts and Brown (2005) remind us about the dual nature of research which may be either empowering and liberating or oppressive and sustaining domination of some groups over the others, so for anti-oppressive research "good intentions are never enough" since the purpose of anti-oppressive research is to challenge the present state of affairs and lead to resistance (p.260). Anti-oppressive researchers treat all knowledge as socially constructed, political and negotiated by power relations when "truth" does not exist independently, for it is "created, it is multiple: truth does not exist, it is made" (Potts \& Brown, 2005, p. 261). Anti-oppressive researchers do not simply collect data and information; they build long-term relationships with the communities as if they "may be in relationship with people for life" (Potts \& Brown, 2005, p. 263). Anti-oppressive research does not follow a linear Western algorithm of problemsolving when researchers focus predominantly on the outcomes; anti-oppressive research should strive not only for desired outcomes but also focus on the anti-oppressive nature of the process itself by contemplating and building relationships (Potts \& Brown, 2005).

herising (2005) introduces the notion of "thresholds of passageways" as negotiable spaces of entry into communities; these thresholds demarcate the boundaries between the researcher and the participants and should be viewed as a place where there are no fixed identities and origins, which is similar to Bhabha's (1994) concept of the "third space" and "in-betweeness" where the idea of origins is contested. herising (2005) stresses the importance of finding access to these "passageways" without resorting to former colonial strategies; in addition, she questions the contested claims and discussions regarding greater accountability on the part of a researcher who is supposed to unpack his or her biases, which may be masked under the notion of "reflexivity". herising (2005) expresses some doubts regarding the idea that one can be fully aware of his or her political and cultural biases and make them fully visible to the others; on the other hand, the overemphasis on biases may lead away from more important inner socio-political tensions of research. In contrast, Andreotti (2011) views "self-reflexivity" as a possibility for a researcher to become aware of the biases and try to avoid them instead of making them visible. The right of entry or finding passages into another's community should not be taken for granted (herising, 2005). The positionality of the researcher thus becomes an ambiguous matter irrespectively of whether he or she is viewed as an insider or an outsider because the researcher initially is vested with power, so critical research in marginal communities should negotiate the nature of power and authority associated with researcher 
status: "we trace the nuances of the politics of location as a means of dislocating the researcher from the threshold" (herising, 2005, p.133). Pratt (1991) introduced the idea of "contact zones" as places where cultures meet in the context of disbalanced power relations, which may provoke potential conflicts and anger, but at the same time, these places may contribute to future learning and mutual knowledge construction (as cited in Parker Webster \& John, 2010).

Swadener and Mutua (2008) prefer to replace "postcolonial" as a linearity term with "postcolonial" to reflect the interaction between past and present (as cited in Parker Webster \& John, 2010). They suggest implementing Vygotsky's theory of cognitive development as socially situated and apply the notion of "zone of proximal development" to collaborative research in postcolonial context. Accordingly, everyone, irrespective of insider or outsider status, may act at one time as a learner and at other times as a teacher or a more experienced peer who may assist other participants in terms of learning and knowledge production. They call it a "third space" of negotiation in postcolonial research where the unequal relations of power between researchers and Indigenous participants may be reconsidered on more fair and equal terms (Parker Webster \& John, 2010). They suggest moving away from established dichotomies colonizer/colonized or Western knowledge/Indigenous knowledge, and rather view a collaborative research as an ever fluid and shifting interchange between learners and more knowledgeable peers when everyone can be both (as cited in Parker Webster \& John, 2010).

The research agenda for ethnographic studies shifted from gathering data by means of informants to understanding the research as a cooperation with the participants, and finally to realization that co-membership is not complete without appreciating and legitimizing the knowledge and voices of others (Montero-Sieburth, 1997). Decolonizing research on language maintenance and loss views participants as co-constructors not merely as data providers. The results of research projects should be disseminated among immigrant communities as well as among English speaking audience, and finally, the research results have a broad scope of applications and consequences for immigrant parents and their children, heritage language learners, educators and policy makers.

\section{REFLECTIVE NARRATIVES AND INTERVIEWS IN HERITAGE LANGUAGE MAINTENANCE AND LOSS RESEARCH}

Narrative inquiry as a method has wide application in a variety of disciplines and fields of research (Clandinin \& Connelly, 2000; Phillion \& He, 2007; Trahar, 2011). Narrative inquiry as a "way of understanding experience" happens in collaboration between researchers and participants in a specific time, place and social context which in combination create the "threedimensional narrative inquiry space" (Clandinin \& Connely, 2000; Clandinin, Huber, Steeves \& $\mathrm{Li}, 2011$ ). Engaging in the process of narrative inquiry requires gazing "inward and outward, backward and forward" which means focusing on inner feelings and emotions in a broader social context moving continually between past and present (Clandinin \& Connelly, 2000).

Reflective narratives are probably one of the most appropriate methods in research on heritage languages aimed not at measuring language proficiency or retention in terms of literacy, but focusing on exploring human experiences and challenges of living with the loss (if they do not speak their heritage languages) or challenges, failures and successes of being, living and functioning in more than one languages in a new country of residence. Phillion and He (2007) state that the priority of narrative inquiry in language teaching and learning is to focus on a life context rather than some purely linguistic issues; narrative inquiry in English 
language teaching provides us with "different ways of thinking about language learning than might be found in traditional research texts" (p.1010). If a particular language is under consideration, then researchers may have a collective narrative weaved by a group of people belonging to the same linguistic community, so narratives are not limited to only individual accounts (Ochs, 2007). Narrative inquiry views language learning experience not simply as an acquisition of some skills or subject but as "the learning of life" (Phillion \& He, 2007, p. 1005).

Narratives are not only about telling and listening to the stories, for they can be productive and enlightening regarding our past experience that seemed incomplete or incomprehensible, so our narratives of the past experience contribute to building our future actions and endeavours (Ochs, 2007). Narrative inquiry as "stories lived and told" (Clandinin \& Connelly, 2000) can provide the opportunity to relive with the participants what they experience on a daily basis without being too intrusive into their routine; by "connecting the word and the world" (Auerbach, 1995, p. 15), researchers get a glimpse into participants' life experience. Narrative inquiry begins not with formulation of some hypothesis or theory that need to be tested or supported with evidence (Clandinin \& Rosiek, 2007), but with personal experience of the researchers and participants; experience as a central category of inquiry permeates every stage of the process from data collection to research text creation (Phillion \& He, 2007). At the same time, Kerby (1991) points out the dual nature of the word experience in English as a single event and as a general notion, but cautions that our narratives cannot "duplicate original experiences, as though now we could relive them precisely as they once were" (p. 22).

Reflection is an inseparable part of our human reality because we usually act and then reflect on our actions (Ochs, 2007); however, if we are still in the middle of our experience or we are still fresh from it, our reflection may be biased, incomplete, or emotional. If we engage in reflection on our past actions and experiences, the results can be more productive in terms of our future actions. Clandinin and Connelly (2000) call this ongoing reflection "wakefulness" to emphasize the importance for the researcher to be constantly aware of the context, field experience, and three-dimensional narrative inquiry space. Researchers in narrative inquiry should act as active listeners who treat every story as a new discovery (Coles, 1989).

Stories are of paramount importance in the narrative inquiry process. Kouritzin (2006) points out that "while statistics and experiments convince institutions, policy-makers, and governments, stories convince individuals. Therefore, in order to change people's minds, in order to change people's hearts, we must engage them with other people's stories" (p. 6). Phillion and He (2007) define stories as "the phenomena of inquiry" while narrative is "the method of inquiry" (p.1008), while Clandinin and Connelly (2000) understand narrative as "both phenomena under study and method of study" (p.4). In a very poetic and precise manner, Neumann (1997) defines the unsurpassed value of stories both in her professional academic research and in her private family life within the context of her family past history of survival in Holocaust:

Stories, to me, are the sense and meaning we derive from ourselves and our lives, for ourselves and for others. They appear less in the clear, hard, textually rendered lines of setting and event, action and plot, movement and sequence, plan and accomplishment, than in the often fragmented, even wordless expressions of experience and emotion. Stories are what we feel and tell ourselves, and how we know our pasts, even in the contexts of our present-day lives. We also tell these stories - of ourselves and our pasts, with words and without - to others in our lives (Neumann, 1997, p. 109). 
Neumann (1997) asserts that researchers intangibly express their life stories, identities and passions through their scholarship, which presumably should be separated from personal life.

Every person in narrative inquiry is potentially viewed as a resourceful story-teller or a narrator with a collection of various stories. Coles (1989) applying narratives in psychiatry, treated his patients as reservoirs of stories that revealed in many cases the underlying causes of their problems and gave clues to their treatment. At the same time, researchers should not assume that they own peoples' stories:

The people who come to see us bring us their stories. They hope they tell them well enough so that we understand the truth of their lives. They hope we know how to interpret their stories correctly. We have to remember that what we hear is their story (Coles, 1989, p. 7).

Instead of trying to define the ownership of the stories told and retold, Clandinin and Connelly (2000) suggest the term "relational responsibility".

Narratives appeal to researchers for several reasons. First, narrative inquiry is beneficial in terms of its experiential qualities (Phillion \& He, 2007). Kanno (2003) points out that narratives offer the opportunity to hear "the actor's own voice" (p.11). For instance, Norton (2000) justifies her choice of narrative methods by the fact that all previous research on language learning and identity did not manage to convey "the voices of particular learners, their distinctive histories, their unique desires for the future" (p. 48). In addition, narratives allow researchers if not fully "relive" their participants' past experiences then at least approximate as closely as possible to what it feels like, whereas other methods offer more distant one-sided accounts on part of the participants with little possibility of engagement for researchers. Lugones (1987) coins the term which is applicable to narrative inquirer's task "travelling to someone's world" as a way to realize "what it is to be them and what it is to be ourselves in their eyes" (p.17). Despite the inappropriateness of making generalizations in narrative inquiry, Ely (2007) emphasizes the possibility of "lifting up" to some potential "metathemes" which will resonate with some broad social context.

In order for narrate inquiry to be effective in research against oppressive systems in society, several conditions are necessary. Clandinin and Rosiek (2007) recommend educating researchers who are involved in narrative inquiry for social justice, including multiple voices and stories in the narrative texts, and promoting interdisciplinary dialogue to seek constructive feedback and critique.

Despite obvious advantages of reflective narratives for decolonizing qualitative research, many scholars voice their concern regarding potential challenges and drawbacks of this method. Our personal narratives are shaped by our age, gender, present emotional state and mood, so the level of subjectivity is quite high; consequently, the same life event may be transformed into numerous different narratives (Zinsser, 1987) even if people who experienced it were close family members; consequently, Bruner (2004) maintains that "any story one may tell about anything is better understood by considering other possible ways in which it can be told" (p. 709). Kanno (2003) at the end of her longitudinal research project interviewed some people close to her participants and found out some new perspectives about the events she had known before, so even ten years or so of personal interactions and relations failed to provide a complete understanding of their life experiences; on the other hand, 
naturally, other person's account of the same life event would be shaped in a different narrative. Because all the stories are incomplete and partial reflections of some fragmented past events, narrative endings are open for alternative interpretations by the reader (Clandinin \& Murphy, 2009).

Clandinin and Rosiek (2007) mentions Dewey's concept of selective experience that poses a challenge for both the participants as to which stories they choose to tell, and for the researcher as to which stories they should include in the research texts. In terms of language maintenance and loss, it is extremely difficult to select the best, most significant and eloquent stories since languages are an integral part of one's life; in case of language loss, it is virtually impossible to trace or pin down the exact moment or story when the loss occurred, on the other hand, with language maintenance it is an everyday continuing struggle which is not reduced to a couple of stories, rather there could be several unforgettable moments that may be shaped into stories and further weaved into a research text. With narrative inquiry it may also be challenging to trace a specific phenomenon or problem since our life stories usually involve not just us as actors, but some other people and overlapping themes which contributed to our past experiences.

Another potential difficulty of narrative inquiry is limited time in the field even in case of longitudinal studies. Clandinin and Connelly (2000) warn researchers that they can enter the life of their participant only at some specific point in time, so all retelling and interpretations of other's experiences are incomplete, arbitrary and tentative (van Manen, 2002); researchers do not have the privilege to know their participants' past and future lives, so the "continuity" (Clandinin \& Connelly, 2000) is deemed to be interrupted. Moreover, in some cases the researchers may present as facts in their final research texts what appeared to be only nuanced implied messages in the participants' narratives (Clandinin \& Connelly, 2000).

Neumann (1997) discovered a power of untold stories that are only articulated with silence, but despite their intangibility, they contribute to a person's life narrative by helping to survive or cope with some dramatic events; consequently, researchers may be unaware of such silent stories and their values will be left behind the interpretive context.

Taking into account the deep personal and even autobiographical nature of the narrative inquiry, researchers run the risk of overlooking the broad social context their work is supposed to address; as a result, they may be accused of narcissism (Clandinin \& Connelly, 2000). In addition, lack of clear boundaries and binaries sometimes may be considered as a problem in narrative inquiry, but in fact due to uniqueness of every story, narrative dichotomy can be created by the contradictory life experiences told as stories (Clandinin \& Rosiek, 2007).

Novice researchers may struggle trying to apply narrative inquiry method since, consciously or not, they may be under the influence of "grand narrative" (Clandinin \& Connelly, 2000) and seek to rely on some sound theoretical framework and definite criteria for evaluation which are not typical for narrative method. Narrative inquiry is not evaluated based on validity, generalizability or possibility for replication because every human story is unique in itself. Clandinin and Connelly (2000) note that criteria for evaluating narrative inquiry are still in the process of being developed.

In the research on heritage languages if the researcher and the participants do not share the same language or participants are not fully proficient in English to convey their emotions, feeling and experiences, there is always a danger of misinterpreting people's stories and 
narratives in the process of translation due to cultural and linguistic differences. Lincoln and Gonzalez y Gonzalez (2008) propose a bilingual research text as a possibility to give voice to local communities who may not speak the dominant language. They claim that if the results of research are to be disseminated among participants as well, it would be more beneficial to keep their words in the original language. At the same time the difficulties of adequate translation are addressed since often the true meaning is if not lost than may be changed in translation.

Another possible limitation of narrative inquiry is related to its temporality, namely in terms of exploring and interpreting some past events. Kerby (1991) suggests two approaches to the past: one is more "linear", measured in hours, days, and years, while the other one is more "phenomenological-existential" which is appropriate for narrative inquiry. In interpreting our past, our imagination and memory could be misleading, making us to believe or wish to believe that events happened exactly in the way we think, but our past is fragmented and incomplete in comparison with our long human life (Kerby, 1991). Atkinson and Silverman (1997) in their criticism of overwhelming "empowerment" of narrative inquiry, state that "life narratives, whether they are retrospective or prospective accounts, are always pastiche, as it were" (p. 319). Greene (1995) echoes that "there is always a gap between what we are living through in our present and what survives from our past" (p. 20-21).

Clandinin and Connelly (2000) claim that narrative inquiry is a two-way interaction when a researcher is working not only with the participants' life stories, but also confront his or her own past experiences, that is a researcher should be willing to disclose some private or even secret experiences; it is impossible to remain a silent observer. Consequently, another challenge could be for researchers to expose themselves and become vulnerable; not everyone is ready to engage in this activity and open his or her soul; to get involved in this risky endeavour of mutual sharing, it is extremely important to know your participants well and establish the relationships based on trust and sincerity. In order to know your participants well, it may be necessary to spend an extensive amount of time in the fieldwork, which may be viewed as a limitation in case of time constraints. On the other hand, even long-term relationship may not translate in equal and open positionlaities of researcher and the participants. Norton (2000) addressees her struggle to avoid "teacher-student" relationships with her female participants because they initially met in the context of unequal power relations. She mentions the complexities of building and defining her relationships with the participants and the feeling of "betraying a confidence" when she was acting as a researcher from a position of power by providing her feedback and comments. Establishing close personal relations in narrative inquiry is necessary in order for the researcher to "relive" with the participants their life events in the process of interactions, creating field notes and research texts.

Fine (1994) identifies another risk of potential "romanticizing of narratives and the concomitant retreat from analysis" (p. 80). Atkinson (1997) criticizes the preoccupation of narratives and interviews with personal life experiences claiming that they go beyond the methodological limits and perform almost "therapeutic and emancipatory" functions, which replace analysis when misuse of narratives becomes "a surrogate form of liberal humanism and a romantic celebration of the individual subject" (p.335). Narrative inquiry is just one out of many possible conventional ways of representations, so it should not be given priority (Atkinson, 1997). 
Interviews may be viewed as a medium of data collection for narrative inquiry; in other words, in our "interview society (Atkinson \& Silverman, 1997), narratives can be considered as one of the possible products of interviewing. Even though on the surface interviews seem to be just a way of asking and answering questions, something we engage in our everyday life, in qualitative research, professional interviews require skills to deal not only with specific research objectives, but also with issues of ethics, interpersonal and intercultural communication.

Interviewing is one of the most common methods of data collection in qualitative research (Fontana \& Frey, 1994; Atkinson \& Silverman, 1997; Doody \& Noonan, 2013). The popularity of this method in qualitative research can be explained by often simplistic understanding of interviews as mere conversations popularized by mass media and talk shows in our "interview society" (Atkinson \& Silverman, 1997); therefore, this method seems too easy and accessible to everyone willing to engage in interactions with others when all that is necessary is "good intentions (that is, to give voice to the voiceless) and the ability to listen and then to transform into a reduced verbal text what one has heard" (Sandelowski, 2002, p. 105). Although interviews are considered to be "gold standard" for qualitative data collection (Silverman, 2000 as cited in Sandelowski, 2002, p. 105), there has been an unjustifiable tendency to prioritize this particular method while neglecting other categories of data which eventually does not lead to high quality research and knowledge advancement (Sandelowski, 2002).

Researchers usually have to choose from or even combine three possible models of interviewing: structured, unstructured or open-ended, and semi-structured (Fontana \& Frey, 1994; Doody \& Noonan, 2013). In research on language maintenance, structured interviews are the least appropriate since they focus on a very narrow way of representing participants' answers and do not provide a space for openness and sharing life narratives.

Scheibelhofer (2008) emphasize the benefits of "problem-centered interviews" in qualitative research involving some autobiographical aspects because this type of interviews opens with a broad introduction offering a participant to start with a narrative beginning which is later elaborated on with the help of semi-structured part. Longitudinal qualitative interviews are the most insightful if there is a need to understand changes and developments among the same participants over a period of time (Hermanowicz, 2013) , and may be applicable in terms of research on language maintenance and loss which occurs not as a single specific event but more like a long process, often invisible to those involved.

The most obvious advantages of employing interviewing as a method of data collection are the opportunities for participants to choose and share the information they consider important; to accumulate direct quotes and words of the participants which may become part of the research text; the opportunity for clarification and elaboration on the issues that seem to be crucial for understanding the interviewees' experiences; a rewarding experience for participants in terms of self-reflexivity and analyzing their past; finally, some groups interviews are helpful if people are illiterate in the language chosen for the interview (Doody \& Noonan, 2013).

Despite traditional assumptions regarding the role of a researcher as an objective listener only, Fontana and Frey (1994) advise engaging in a real conversation with the participants in order to establish more emphatic and equal relationships: "as we treat the other as a human being, we can no longer remain objective, faceless interviewers, but become human beings and must disclose ourselves, learning about ourselves as we try to learn about the other" (Fontana \& Frey, 1994, p. 374). However, Lincoln and Denzin (1994) question the possibility of knowing 
the other and being able to "speak authentically of the experience of the Other" (p. 577). Atkinson (1997) expresses his disbelief regarding the assumption that inner world and experience of other people can be evaluated and made visible via interviews or dialogues. Due to peoples' subjective perception of their multiple identities, Kundera (1991) denies the possibility of stable tangible selves in a postmodern reality:

our self is a mere illusion, ungraspable, indescribable, misty, while the only reality, all too easily graspable and describable, is our image in the eyes of others. And the worst thing about it is that you are not its master (p.143 as cited in Atkinson \& Silverman, 1997, p. 308).

These doubts regarding the possibility of adequate representation of the "other" were also defined as "the representational crisis" peculiar to the qualitative research in general (Denzin \& Lincoln, 1994).

Interviews are quite time-consuming and sometimes may seem like intrusion especially if the focus of the interview is a very sensitive issue; in addition, participants may be willing to provide socially acceptable or expected answers instead of their real ones, thus disguising the nature of final interpretation and research text (Doody \& Noonan, 2013). In addition, researchers run the risk of "taking what people say in interviews at face value as revealing what is behind the face" forgetting that interviewees may have their own hidden agenda and motivations to justify their actions and behaviour or simply present themselves in a positive light (Sandelowski, 2002, p. 106).

It may be difficult to establish trust with the participants and easy to lose the gained trust (Fontana \& Frey, 1994); on the other hand, if a researcher has very close or friendly relationships with the participants, it may be challenging to conduct interviews because frequently they transform into informal conversations (Clandinin \& Connelly, 2000; Haahr, Norlyk \& Hall, 2014; Fontana \& Frey, 1994), so it could be difficult to sustain professional and ethical behaviour on part of the researcher: "the researcher-participant relationship is decisive and constitutes a major challenge, running the risk of being either too close or too distant" (Haahr et al., 2014, p. 6).

Finally, there is always uncertainty regarding the accuracy of transcripts which depends on the professional knowledge, personal biases and other subjective characteristics of the researcher, the interviewer, the transcriber, the interviewee, the location and quality of the recording (Mero-Jaffe, 2011). It is a debatable issue as to which transcripts, naturalized or denaturalized, best match the purpose of the research. The major concern with naturalized transcripts is their potential to embarrass participants while doing member checks. Member validation of the transcripts aims not only to improve accuracy of representation, but also to empower the participants and decrease power imbalances between the researcher and the interviewees; on the other hand, interviewees may change significantly the data and influence the final interpretive analysis and research text since they are in control to make changes, add or delete comments (Mero-Jaffe, 2011). Member validation is probably not the most reliable way to ensure accuracy of representation but it has the value of "providing an opportunity to collect additional data about members' responses to a new phenomenon, namely, the researcher's account" (Sandelowski, 2002, p. 108). 
Despite the popularity of interviews as qualitative method of data collection, researchers should also be aware and alert of the limitation of this method and if possible, do not rely exclusively on interviewing in the research process and do not dismiss other methods of data collection. Sandelowski (2002) advises that "when identity politics, postmodern subjects, and multiple and divided selves confront one other in the interview society, qualitative researchers must decide how they will treat the interview and show that they are aware that they have made a decision" (p.107).

\section{CONCLUSION}

Writing is difficult, even more so research writing which needs to be sensitive and accommodate numerous voices, perspectives and stories. If a researcher chooses a formal and standard approach to research, defining a clear research agenda, planning ahead all the details and even expecting some predetermined conclusions, then his or her task is easier; however, this kind of research is boring. It is more rewarding to explore a constantly changing phenomenon, which probably does not even have a name yet, but which may become a sudden moment of "shock" (Greene, 1995) when perceived and transformed into words despite the claim that "language kills whatever it touches" (van Manen, 2002, p. 244).

Van Manen's (2002) metaphor of "writing in the dark" is also applicable to the qualitative research involving personal interviews and life narratives, in a sense that as a researcher, you never know where you are heading for and whether you are going to find some answers to your predetermined questions (if those answers ever exist), and how your participants' unique narratives may suddenly puzzle, surprise, embarrass you or even turn around the whole process of research. In fact, a qualitative researcher is in a perpetual and perennial "darkness" and hesitation, but with every participant's voice, with every research endeavour, I believe we may get if not bright light of awareness and enlightenment, then at least a glimpse of light projected in our future quest for more glimpses. The best thing about a qualitative research is that it never ends, it is never complete, it does not provide definite numbers and data to be verified, it is always open-ended, for it provides researchers with the opportunity of a life-long quest and passion.

\section{References}

Absolon, K. \& Willett, C. (2005). Putting ourselves forward: Location in Aboriginal research. In L. Brown \& S. Strega (Eds.), Research as resistance: Critical, Indigenous, and anti-oppressive approaches (pp. 97-126). Toronto: Canadian Scholars' Press.

Andreotti, V. (2011). Actionable postcolonial theory in education. New York: Palgrave Macmillan.

Appadurai, A. (1997). Modernity at large: Cultural dimensions of globalization. Delhi: Oxford University Press.

Appadurai, A. (2006). The right to research. Globalization, Societies and Education, 4(2), 167-177. doi: $10.1080 / 14767720600750696$.

Atkinson, P. (1997). Narrative turn or blind alley? Qualitative Health Research, 7, 325-344. doi: $10.1177 / 104973239700700302$.

Atkinson, P. \& Silverman, D. (1997). Kundera's immortality: The interview society and the invention of the self. Qualitative Inquiry, 3, 304-325. doi: 10.1177/107780049700300304.

Auerbach, E.R. (1995). The politics of the ESL classroom: Issues of power in pedagogical choices. In J.W. Tollefson (Ed.), Power and inequality in language education (pp.9-33). New York: Cambridge University Press.

Baker, V. J. (2005). English and /or mother-tongue instruction: Ambivalence in post-apartheid South Africa. In R.Hoosain \& F. Salili (Eds.), Language in multicultural education (pp. 115-133). Greenwich: Information Age Publishing.

Bhabha, N.K. (1994). The location of culture. London and New York: Routledge. 
Bogdan, R.C. \& Biklen, S.K. (2003). Qualitative research for education: An introduction to theory and methods (4th ed.). Boston: Allyn and Bacon.

Brown, L. \& Strega, S. (2005). Introduction: Transgressive possibilities. In L. Brown \& S.

Strega (Eds.), Research as resistance: Critical, Indigenous, and anti-oppressive approaches (pp. 1-17). Toronto: Canadian Scholars' Press.

Bruner, J. (2004). Life as narrative. Social Research, 71 (3), 691-710.

Clandinin, D.J. \& Connelly, F.M. (2000). Narrative inquiry: Experience and story in qualitative research. San Francisco: Jossey-Bass, Inc.

Clandinin, D.J., Huber, J., Steeves, P. \& Li, Y. (2011). Becoming a narrative inquirer: Learning to attend within the three-dimensional narrative inquiry space. In S. Trahar (Ed.), Learning and teaching narrative inquiry: Travelling in the borderlands (pp.33-51). Amsterdam/Philadelphia: John Benjamins Publishing Company.

Clandinin, D.J. \& Murphy, M.S. (2009). Comments on Coulter and Smith: Relational ontological commitments in narrative research. Educational Researcher, 38, 598-602. doi: 10.3102/0013189x09353940.

Clandinin, D. J. \& Rosiek, J. (2007). Mapping a landscape of narrative inquiry: Borderland spaces and tensions. In D. J. Clandinin (Ed.), Handbook of narrative inquiry: Mapping a methodology (pp. 35-75). Thousand Oaks, CA: Sage Publications.

Coles, R. (1989). Stories and theories. In R. Coles, The call of stories: Teaching and the moral imagination (pp. 130). Boston: Houghton Mifflin.

Creswell, J.W. (2007). Qualitative inquiry and research design: Choosing among five approaches. Thousand Oaks: Sage Publications.

Delgado-Gaitan, C. (1997). Dismantling borders. In A. Neumann \& P.L. Peterson (Eds.), Learning from our lives: Women, research, and autobiography in education (pp.37-51). New York: Teachers College Press.

Denzin, N.K. \& Lincoln, Y.S. (1994). Introduction: Entering the field of qualitative research. In N.K. Denzin \& Y.S. Lincoln (Eds.), Handbook of qualitative research (pp. 1-17). Thousand Oaks: Sage Publications.

Doody, O. \& Noonan, M. (2013). Preparing and conducting interviews to collect data. Nurse Researcher, 20 (5), 28 32.

Dorian, N.C. (1999). Linguistic and ethnographic fieldwork. In J.A. Fishman (Ed.), Handbook of language and ethnic identity (pp.25-41). New York: Oxford University Press.

Ely, M. (2007). In-forming representations. In D.J. Clandinin (Ed.), Handbook of narrative inquiry: Mapping a methodology (pp. 567-598). Thousand Oaks, CA: Sage Publications, Inc.

Fine, M. (1994). Working the hyphens: Reinventing self and other in qualitative research. In N.K. Denzin \& Y.S. Lincoln (Eds.), Handbook of qualitative research (pp. 70-82). Thousand Oaks: Sage Publications.

Fishman, J.A. (1991). Reversing language shift: Theoretical and empirical foundations of assistance to threatened languages. Clevedon: Multilingual Matters Ltd.

Fontana, A. \& Frey, J.H. (1994). Interviewing: The art of science. In N.K. Denzin \& Y.S.

Lincoln (Eds.), Handbook of qualitative research (pp. 361-376). Thousand Oaks: Sage Publications.

Greene, M. (1995). Releasing the imagination: Essays on education, the arts, and social change.

San Francisco: Jossey-Bass, Inc.

Haahr, A., Norlyk, A. \& Hall, E. (2014). Ethicl challenges embedded in qualitative research interviews with close relatives. Nursing Ethics, 21(1), 6-15. doi: 10.1177/0969733013486370.

herising, F. (2005). Interrupting positions: Critical thresholds and queer pro/positions. In L.

Brown \& S. Strega (Eds.), Research as resistance: Critical, Indigenous, and anti-oppressive approaches (pp. 127151. Toronto: Canadian Scholars' Press.

Hermanowicz, J.C. (2013). The longitudinal qualitative interview. Qualitative Sociology, 36, 189-208. doi: 10.1007/s11133-013-9247-7.

Ho, M. (2000). The winter hibiscus. In J. Novakovich \& Shapard, R. (Eds.), Stories in the stepmother tongue (pp. 161-178). Buffalo, New York: White Pine Press. 
Hoosain, R. \& Salili, F. (2005). Dimensions of language in multicultural education. In R.Hoosain \& F. Salili (Eds.), Language in multicultural education (pp. 3-9). Greenwich: Information Age Publishing.

Hornberger, N.H. \& Putz, M. (Eds.). (2006). Language loyalty, language planning and language revitalization: Recent writings and reflections from Joshua A. Fishman. Clevedon: Multilingual Matters Ltd.

Jankie, D. (2004). "Tell me who you are": Problematizing the construction and positionalities of "insider" / "outsider" of a "native" ethnographer in a postcolonial context. In K. Mutua \& B.B. Swadener (Eds.), Decolonizing research in cross-cultural contexts: Critical personal narratives (pp. 87-106). Albany, NY: State University of New York Press.

Kanno, Y. (2003). Negotiating bilingual and bicultural identities: Japanese returnees betwixt two worlds. Mahwah, NJ: Erlbaum.

Kerby, A.P. (1991). Time and memory. In Narrative and the self: Studies in continental thought (pp. 15-31). Bloomington, IN: Indiana University Press.

Kouritzin, S. G. (2000). A mother's tongue. TESOL Quarterly, 34(2), 311-324.

Kouritzin, S. G. (2006). Songs from taboo tongues: Experiencing first language loss. Language and Literacy, 8 (1), 1-28.

Kovach, M. (2005). Emerging from the margins: Indigenous methodologies. In L. Brown \& S.

Strega (Eds.), Research as resistance: Critical, Indigenous, and anti-oppressive approaches (pp. 19-36). Toronto: Canadian Scholars' Press.

Kubota, R. (2005). Second language teaching for multilingualism and multiculturalism: Politics, challenges, and possibilities. In R.Hoosain \& F. Salili (Eds.), Language in multicultural education (pp. 31-55). Greenwich: Information Age Publishing.

Lincoln, Y.S. \& Denzin, N.K. (1994). The fifth moment. In N.K. Denzin \& Y.S. Lincoln (Eds.), Handbook of qualitative research (pp. 575-586). Thousand Oaks: Sage Publications.

Lincoln, Y.S. \& Gonzalez y Gonzalez, E.M. (2008). The search for emerging decolonizing methodologies in qualitative research. Qualitative Inquiry, 14(5), 784-805. doi: 10.1177/1077800408318304.

Lugones, M. (1987). Playfullness, “word”-travelling, and loving perception. Hypatia, 2 (2), 3-19.

Macedo, D. \& Bartolome, L.I. (2014). Multiculturalism permitted in English only. International Multilingual Research Journal, 8, 24-37. doi: 10.1080/19313152.2014.852426.

Mero-Jaffe, I. (2011). 'Is that what I said?' Interview transcript approval by participants: An aspect of ethics in qualitative research. International Journal of Qualitative Methods, 10 (3), 231-247.

Montero-Sieburth, M. (1997). The weaving of personal origins and research: Reencuentro y reflexion en la investigacion. In A. Neumann \& P.L. Peterson (Eds.), Learning from our lives: Women, research, and autobiography in education (pp.124-149). New York: Teachers College Press.

Mutua, K. \& Swadener, B.B. (2004). Introduction. In K. Mutua \& B. B. Swadener (Eds.), Decolonizing research in cross-cultural contexts: Critical personal narratives (pp. 1-23). Albany, NY: State University of New York Press.

Neumann, A. (1997). Ways without words: Learning from silence and story in post-holocaust lives. In A. Neumann \& P.L. Peterson (Eds.), Learning from our lives: Women, research, and autobiography in education (pp.91-120). New York: Teachers College Press.

Norton, B. (2000). Identity and language learning: Gender, ethnicity and educational change. Harlow: Pearson Education Limited.

Ochs, E. (2007). Narrative lessons. In L. Monaghan, \& J.F. Goodman (Eds.), A cultural approach to interpersonal communication: Essential readings (pp.41-49). Malden, MA: Blackwell Publishing.

Olson, G.A. \& Worsham, L. (1998). Staging the politics of difference: Homi Bhabha`s critical literacy. A Journal of Composition Theory, 18 (3), 361-391.

Parker Webster, J. \& John, T.A. (2010). Preserving a space for cross-cultural collaborations: An account of insider/outsider issues. Ethnography and Education, 5(2), 175-191. doi:10.1080/17457823.2010.493404.

Phillion, J. \& He, M.F. (2007). Narrative inquiry and ELT research. In J. Cummins \& C.

Davidson (Eds.), International handbook of English language teaching (pp.1003-1016). New York: Springer. 
Potts, K. \& Brown, L. (2005). Becoming an anti-oppressive researcher. In L. Brown \& S. Strega (Eds.), Research as resistance: Critical, Indigenous, and anti-oppressive approaches (pp. 255-286). Toronto: Canadian Scholars' Press.

Rodriguez, R. (1983). Hunger of memory: The education of Richard Rodriguez. New York: Bantam Books.

Sandelowski, M. (2002). Reembodying qualitative inquiry. Qualitative Health Research, 12 (1), 104-115.

Scheibelhofer, E. (2008). Combining narration-based interviews with topical interviews: Methodological reflections on research practices. International Journal of Social

Research Methodology, 11 (5), 403-416. doi: 10.1080/13645570701401370.

Skutnabb-Kangas, T. \& Bucak, S. (1995). Killing a mother tongue - how the Kurds are deprived of linguistic human rights. In T. Skutnabb-Kangas, R. Phillipson, \& M. Rannut (Eds.), Linguistic human rights: Overcoming linguistic discrimination (pp. 348-370). Berlin \& New York: Mouton de Gruyter.

Smith, L.T. (1999). Decolonizing methodologies: Research and Indigenous peoples. London \& New York: Zed Books Ltd.

Statistics Canada (2014). Immigrant languages in Canada: Language, 2011 census of population. Retrieved from http://www12.statcan.gc.ca/census-recensement/2011/as-sa/98-314-x/98-314-x2011003_2-eng.cfm.

Trahar, S. (2011). Introduction: Travelling in the borderlands or a story of not quite fitting in. In S. Trahar (Ed.), Learning and teaching narrative inquiry: Travelling in the borderlands (pp.1-13). Amsterdam/Philadelphia: John Benjamins Publishing Company.

van Manen, M. (2002). Writing in the dark. In M.van Manen (Ed.), Writing in the dark: Phenomenological studies in interpretive inquiry. London, ON: The Althouse Press.

Zinsser, W. (1987). Writing and remembering. In W. Zinsser (Ed.), Inventing the truth: The art and craft of memoir (pp. 143-161). Boston: Houghton Mifflin Company. 